\title{
A New Species of the Genus Otacilia Thorell, 1897 (Araneae: Phrurolithidae) from Southern China
}

\author{
Keke Liu, Yuanhao Ying, Yuxin Xiao, Jing Yan, Mengzhen Zhang and \\ Yonghong Xiao* \\ College of Life Science, Jinggangshan University, Ji'an 343009, Jiangxi, P.R. China
}

\section{A B S T R A C T}

A new species, Otacilia dadongshanica Liu, sp. nov. ( $\jmath^{\Uparrow}+$ ) is firstly described from Jiangxi Province, China. The new species is diagnosed and illustrated with photographs. A distribution map is also given.

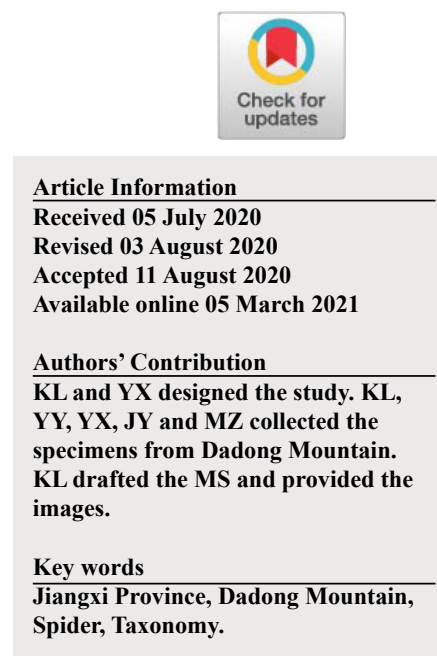

\section{INTRODUCTION}

$\mathrm{T}$ he genus Otacilia Thorell, 1897 has a wide distribution with 99 species only in the Asian regions (World Spider Catalog, 2020). The total number of species in Otacilia has increased approximately $72 \%$ in the past ten years and still continues to grow (Fu et al., 2010; Jäger and Wunderlich, 2012; Wang et al., 2012, 2015; Yang et al., 2013; Fu, 2016; Fu et al., 2014, 2015, 2016a, b; Jin et al., 2016; Jäger and Dimitrov, 2019; Liu et al., 2019; World Spider Catalog, 2020; Zamani and Marusik, 2020). So far there are 74 species (about $75 \%$ of the total) reported from China. Out of these, 70 species have been reported from southern China: Hainan (6 species), Taiwan (2 species), Zhejiang (4 species), Yunnan (10 species), Guangxi (2 species), Guizhou (5 species), Sichuan (8 species), Chongqing (9 species), Hunan (19 species), Hubei (4 species) and Taiwan (1 specie) provinces in southern China ( $\mathrm{Li}$ and Lin, 2016; World Spider Catalog, 2020). No one species were recorded from other provinces in this huge country (World Spider Catalog, 2020).

The genus Otacilia is not easy to be distinguished from Phrurolithus C.L. Koch, 1839 in the past years. In recent years, additional characters were found and documented not only in Otacilia, but also in Phrurolithus (Wang et al., 2015; Fu, 2016; Fu et al., 2016a, b; Jin et al., 2016; Liu et al., 2019; World Spider Catalog, 2020;

\footnotetext{
* Corresponding author: yonghongxiao01@126.com 0030-9923/2021/0003-0801 \$9.00/0

Copyright 2021 Zoological Society of Pakistan
}

Zamani and Marusik, 2020). As more attention was paid in recent years, the definition between them is getting clearer since Zamani and Marusik (2020) published their work. According to morphological and sexual dimorphic characters, Otacilia species can be divided into five species groups including the armatissima group, ambon group, longituba group, and pseudostella group as well as a group of unplaced species (Jin et al., 2016; Liu et al., 2019).

Until now, no Otacilia species have been recorded from Jiangxi province (World Spider Catalog, 2020). However, while studying materials from Dadong Mountain in Jiangxi, we recognised a species new to science, which we describe below.

\section{MATERIALS AND METHODS}

All specimens were collected from Jiangxi Province by Ke-Ke Liu, Yuan-Hao Ying, Yu-Xin Xiao, Jing Yan, and Meng-Zhen Zhang using the sieving method.

Abbreviations

ALE, anterior lateral eye; AME, anterior median eye; $\mathrm{CD}$, copulatory duct; $\mathrm{CO}$, copulatory opening; $\mathrm{CT}$, connecting tube; E, embolus; FE, femur extension; FD, fertilisation duct; GA, glandular appendage; MOA, median ocular area; MP, median plate; MS, membranous sac; PLE, posterior lateral eye; PME, posterior median eye; $\mathrm{PP}$, posterior plate; RTA, retrolateral tibial apophysis; SA, subterminal apophysis; SD, sperm duct; SP, spermathecae; SS, subapical spine; TA, terminal apophysis. 


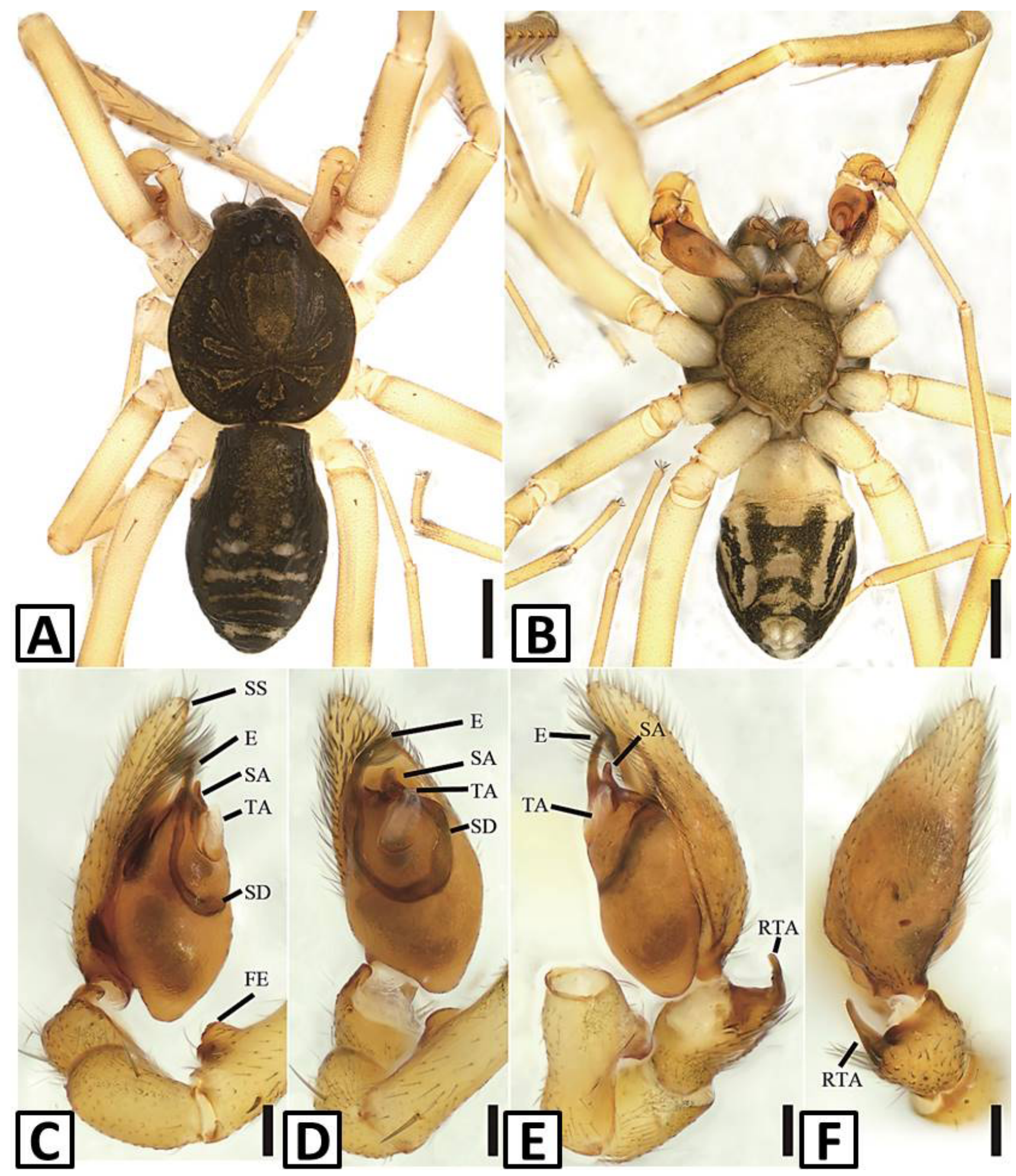

Fig. 1. Otacilia dadongshanica sp. nov., male holotype. A, Habitus, dorsal view; B, Same, ventral view; C, Palp, prolateral view; D, Same, ventral view; E, Same, retrolateral view; F, Same, dorsal view. Scale bars: A and B, $0.5 \mathrm{~mm}$; C-F, $0.1 \mathrm{~mm}$. Abbreviations: DTA, dorsal tibial apophysis; E, embolus; FE, femoral extension; RTA, retrolateral tibial apophysis; SA, subterminal apophysis; $\mathrm{SD}$, sperm duct; SS, subapical spine; TA, terminal apophysis. 
Specimens were examined using a Zeiss Stereo Discovery V12 stereomicroscope with a Zoom Microscope System. Both male palps and female epigynes were detached and examined using a Zeiss Axio Scope A1 compound microscope with a KUY NICE CCD. For photographs of the vulva, the epigynes were first digested with pancreatin for $10 \mathrm{~h}$ of digestion and immerged in $95 \%$ ethanol. Body parts were placed on a clean slide in Silicon for photography. For SEM photographs, the specimens were dried on filter paper and photographed with the ZEISS EVO LS15 scanning electron microscopes under a low vacuum. The specimens were subsequently stored in $75 \%$ ethanol after SEM. All the specimens are deposited in the Animal Specimen Museum, Jinggangshan University (ASM-JGSU).

All morphological measurements were taken using a stereomicroscope (AxioVision SE64 Rel. 4.8.3) and are given in millimetres. The body length of each specimen does not include the spinnerets or the chelicerae. Terminology of the male and female genitalia follows Jäger and Wunderlich (2012), Liu et al. (2019) and Zamani and Marusik (2020). Promarginal and retromarginal teeth on the chelicerae are given as first, second, third, etc. from the base of the fang to the distal groove. Leg spines were documented by dividing each leg segment into two aspects: prolateral (p) and retrolateral (r) and indicating the ventral (v) spines as single (1) or paired (2), e.g., femur I p1111; tibia I v2222.

Family Phrurolithidae Banks, 1892

Genus Otacilia Thorell, 1897

Otacilia dadongshanica Liu, sp. nov. (Figures 1-5)

\section{Type material}

Holotype ô, China: Jiangxi Province, Ji'an City, Jishui County, Dadong Mountain, Yunyin Temple, 27¹5'07.63'N, 115'10'41.08'E, 569 m, 1 December 2018, Ke-Ke Liu, Yuan-Hao Ying, Yu-Xin Xiao, Jing, Yan and Meng-Zhen Zhang leg (Phu-13-1). Paratypes: 13 ㅇ, same data as holotype (Phu-13-2-14).

\section{Description}

Male (holotype): habitus as in Figure $1 \mathrm{~A}$ and B. Total length 2.85, prosoma length 1.38 , width 1.19. Eye diameters: AME 0.09, ALE 0.08, PME 0.07, PLE 0.08. Eye interdistances: ALE-AME 0.02, AME-AME 0.04, PLE-PME 0.07, PME-PME 0.10, ALE-ALE 0.22, PLE-PLE 0.35, ALE-PLE 0.10, AME-PME 0.09, AMEPLE 0.17. MOA 0.23 long, front width 0.18 , back width
0.23. Chelicerae (Fig. 3A, B) with two spines near base (medial ones larger), three promarginal (proximal largest, distal smallest) and five retromarginal (distal largest, $3^{\text {th }}$ smallest) teeth. Endites longer than wide. Labium wider than long. Sternum sub-round, slightly longer than wide, posteriorly pointed. Leg measurements (I-IV): I 6.12 (1.51, 0.52, 1.84, 1.48, 0.77); II 4.84 (1.24, 0.48, 1.28, $1.15,0.70)$; III 3.81(1.05, 0.38, 0.90, 1.01, 0.47); IV 6.43 (1.68, 0.55, 1.50, 1.74, 0.96). Leg spination: femora I-IV with one dorsal spine each; femur I p1111, II p111; Tibia I v22222222, II v2222222; Metatarsus I v2222, II v1222. Opisthosoma elongate elliptical in dorsal view (Fig. 1A, B), length 1.36, width 0.86 ; weak dorsal scutum in anterior half.

Colouration (Fig. 1A, B): prosoma yellow brown to dark brown, with radial, irregular dark brown mottled markings on surface. Fovea distinct, black. Chelicerae, endites, labium and sternum yellow brown. Legs yellow. Opisthosoma yellowish to dark brown, with pair of round and oval markings located on posterior dorsal scutum and three light chevron-shaped stripes on posterior part, and yellowish transverse stripe in front of anal tubercle; venter yellowish to dark brown, with paired dark brown stripes.

Palp (Figs. 1C-F, 3C-G, 4A-C). Femora slightly depressed retrolaterally, with well-developed ventral knob-like extension. Patella unmodified. RTA with stout, triangular base directed upward with slender, slightly curved, blunt apical projection forming right angle with base and pointing forward. Cymbium more than 2 times longer than wide, prolaterally with subapical spine; anterior margin with dense group of thick setae partly covering embolus. Bulb oval, with long U-shaped sperm duct. Embolus spine-like, thick, with broad triangular base, apart from subterminal apophysis and terminal apophysis. Subterminal apophysis straight, thicked, fingershaped, submedial part covered by terminal apophysis, with slightly curved apex, pointed at embolus tip. Terminal apophysis membranous, oval.

Female (Phu-13-2): habitus as in Figure 2A and B, as in male except as noted below. Total length 4.15, prosoma length 1.63, width 1.38. Eye diameters: AME 0.08, ALE 0.09, PME 0.09, PLE 0.10; interdistances: ALE-AME 0.02, AME-AME 0.05, PLE-PME 0.07, PME-PME 0.10, ALE-ALE 0.25, PLE-PLE0.40, ALE-PLE 0.11, AMEPME 0.10, AME-PLE 0.23. MOA 0.27 long, front width 0.22 , back width 0.28 . Opisthosoma (Fig. 2A, B) length 2.44, width 1.44. Legs (Fig. 2A, B) measurements: I 6.77 $(1.75,0.62,2.10,1.55,0.75)$; II 5.53 (1.47, 0.58, 1.58, $1.22,0.68)$; III $4.55(1.20,0.45,1.10,1.15,0.65)$; IV 7.07 (1.96, 0.59, 1.73, 1.94, 0.85). Colouration (Fig. 2A, B): lighter than males. 

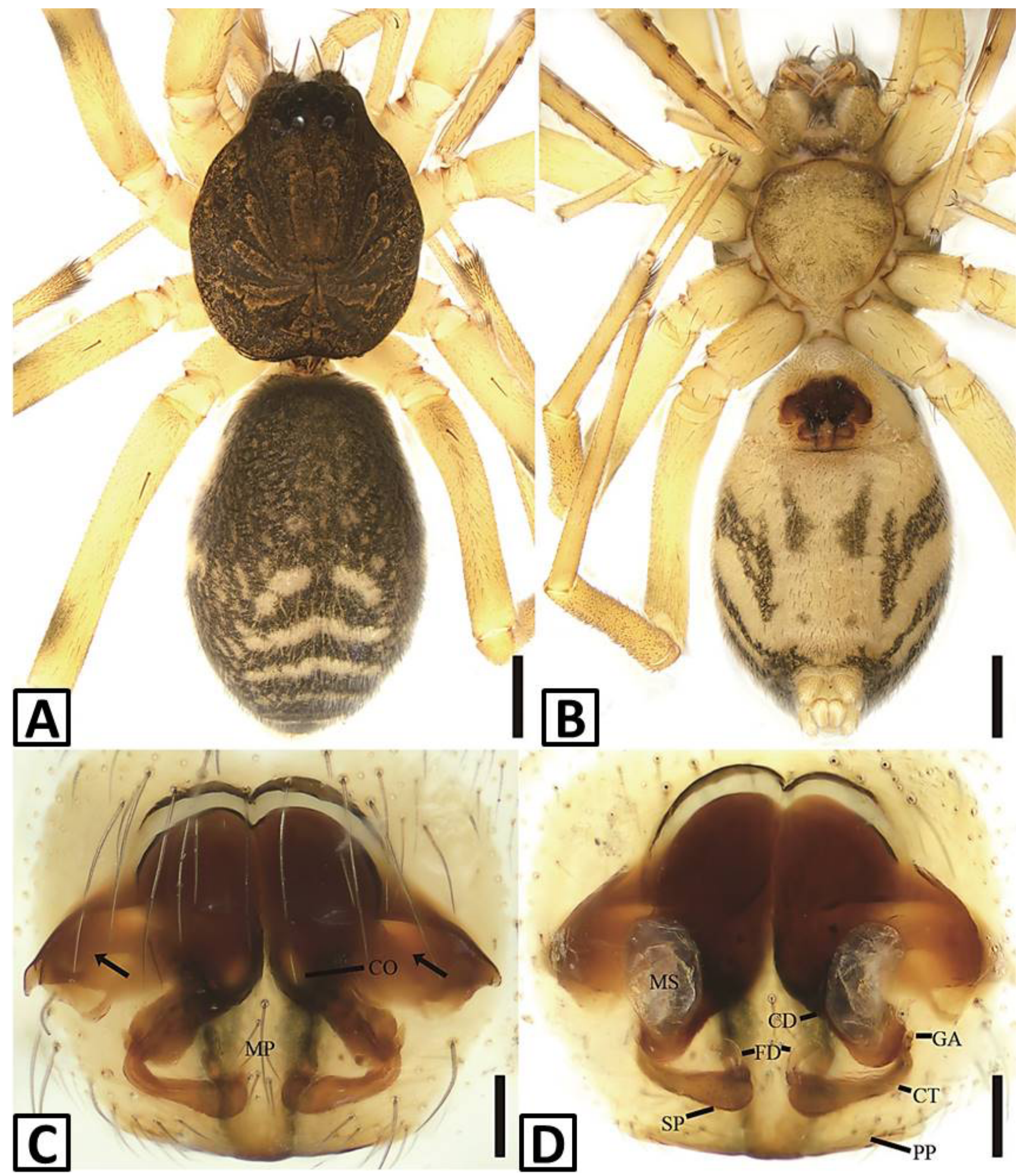

Fig. 2. Otacilia dadongshanica sp. nov., female paratype (Phu-13-2). A, Habitus, dorsal view; B, Same, ventral view; C, Epigyne, ventral view, black arrows showing the slerotized depressed area; D, Vulva, dorsal view. Scale bars: A and B, $0.5 \mathrm{~mm} ; \mathrm{C}$ and D, 0.1 mm. Abbreviations: CO, copulatory opening; CT, connecting tube; FD , fertilization ducts; GA, glandular appendage; MP, median plate; MS, membranous sac; PP, posterior plate; SP, spermathecae. 
Epigyne(Figs. 2C, D, 4D, E). Epigynal plate wing-like, anteriorly with a strongly sclerotized M-shaped margin, medially with concave copulatory openings, laterally with large sclerotized depressed area, posteriorly with sub-triangular median plate; copulatory ducts, glandular appendages, connecting tubes and spermathecae distinctly visible by transparency through integument in intact epigyne. Copulatory ducts broad, declivitous, posteriorly with pair of kidney-shaped transparent membranous sac. Glandular appendages short, anterior-partly covered by membranous sac, located on the anterior of connecting tubes. Connecting tubes short, located between glandular appendages and spermathecae. Spermathecae clavateshaped, slightly separated. Fertilisation duct crescent-like, short, located apically on spermathecae.

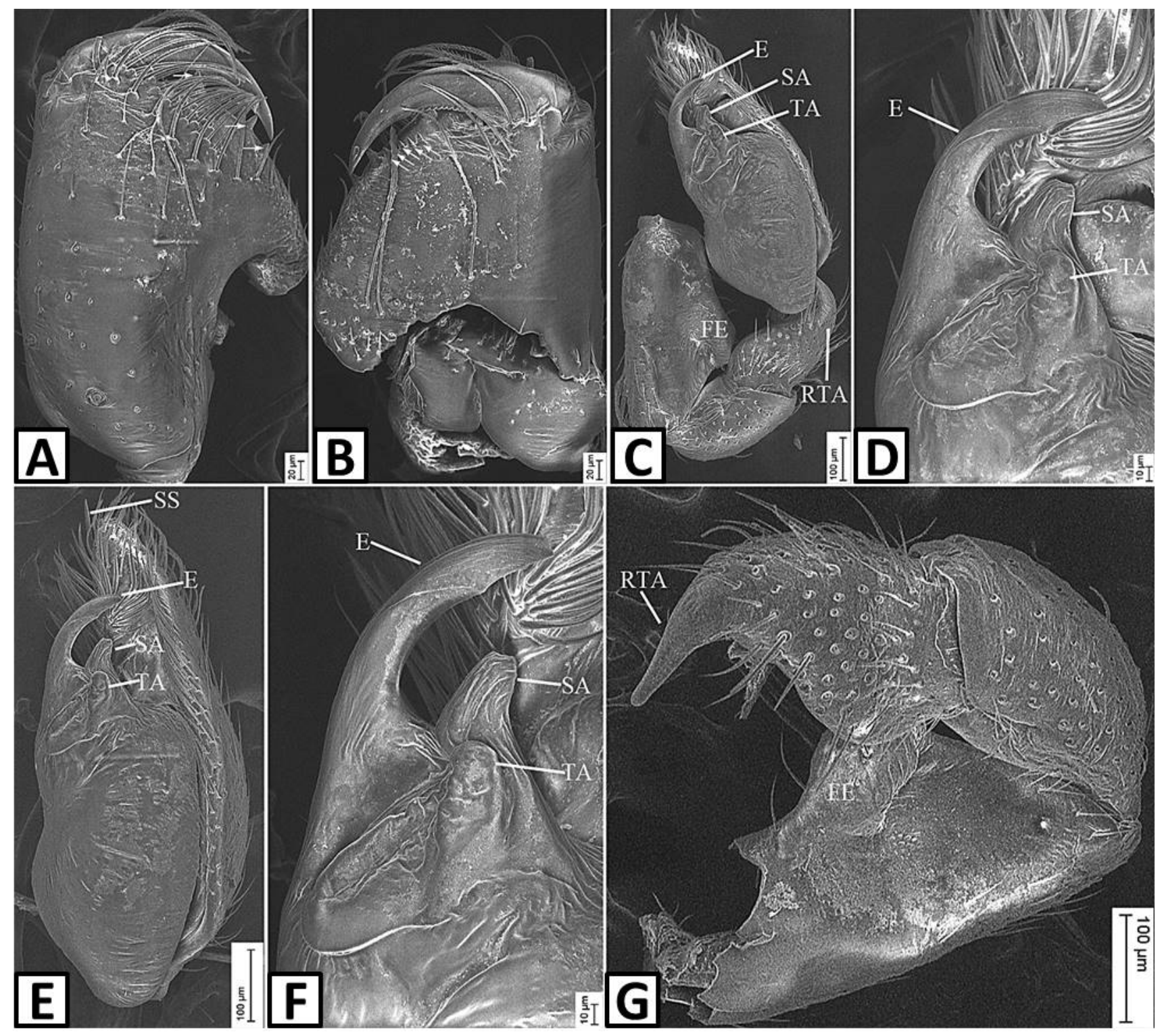

Fig. 3. SEM micrographs of Otacilia dadongshanica sp. nov., male holotype. A, Chelicera, frontal view, white arrows showing the promarginal teeth; B, Same, posterior view, white arrows showing the retromarginal teeth; C, Palp, retroventral view; D, Same, detail of embolus, subterminal apophysis and terminal apophysis; E, same, retrolateral view; F, Same, detail of embolus, subterminal apophysis and terminal apophysis; G, Same, dorsolateral view, detail of retrolateral tibial apophysis. Abbreviations: E, embolus; FE, femoral extension; RTA, retrolateral tibial apophysis; SA, terminal apophysis; SS, subapical spine; TA, terminal apophysis. 


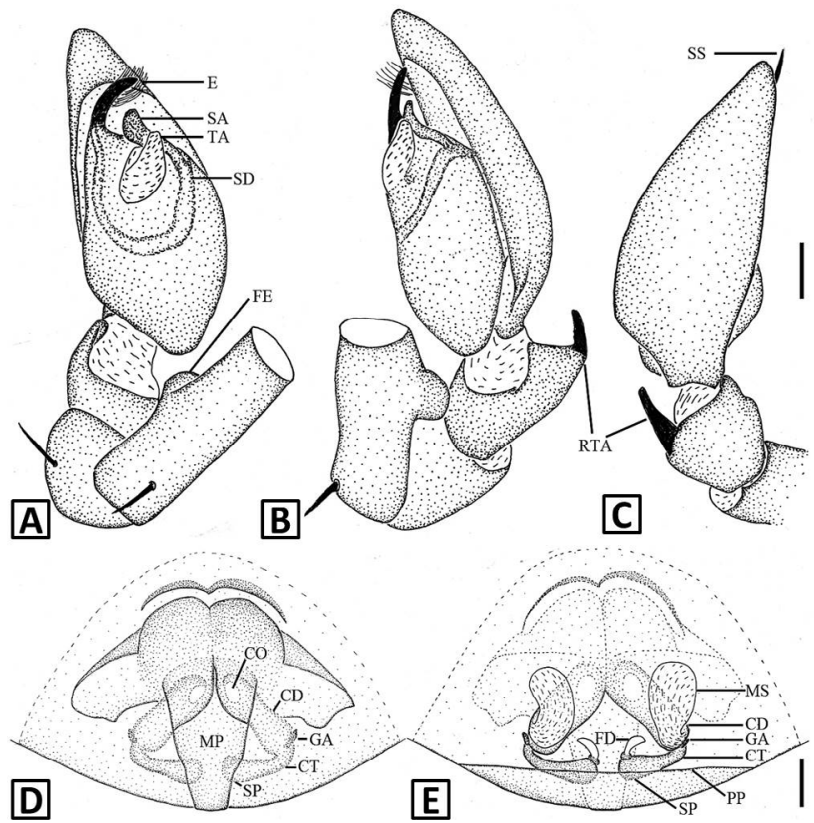

Fig. 4. Otacilia dadongshanica sp. nov., male holotype and female paratype (Phu-13-2). A, Palp, ventral view; B, Same, retrolateral view; C, Same, dorsal view; D, Epigyne, ventral view. E, Vulva, dorsal view. Abbreviations: CO, copulatory opening; CT, connecting tube; E, embolus; FD, fertilization ducts; FE, femoral extension; GA, glandular appendage; MP, median plate; MS, membranous sac; PP, posterior plate; RTA, retrolateral tibial apophysis; SA, subterminal apophysis; SP, spermathecae; SS, subapical spine; TA, terminal apophysis. Scale bars: $0.1 \mathrm{~mm}$.

\section{Etymology}

The specific name refers to the type locality, Chinese Pinyin 'dadongshan'; adjective.

\section{Diagnosis}

The new species differs from Otacilia daweishan Liu et al. by having chelicerae with five retromarginal teeth (Fig. 3A, B) (vs. six). Males are further recognized by the palp with a finger-shaped subterminal apophysis (Figs. 1CE, 3C-F, 4A, B) (vs. triangular), a terminal apophysis with oval base (vs. rounded) and female epigyne with anterior M-shaped sclerotized margin (Figs. 2D, 4D) and large sclerotized depressed area (vs. microwave-shaped anterior margin and weakly sclerotized depressed area).

\section{Distribution}

Known only from Jiangxi Province, China (Fig. 5).

\section{ACKNOWLEDGEMENTS}

We thank Dr Nathalie Yonow for improving the
English of the manuscript. This paper benefited greatly from the helpful comments of Dr. Arnaud Henrard. This study was supported by the Natural Science Foundation of Jiangxi Province (20181BAB214008), the Science and Technology Innovation Project for College Students, the Science and Technology Foundation of Jiangxi Provincial Department of Education (GJJ160753) and the Natural Science Foundation of China (31560592).

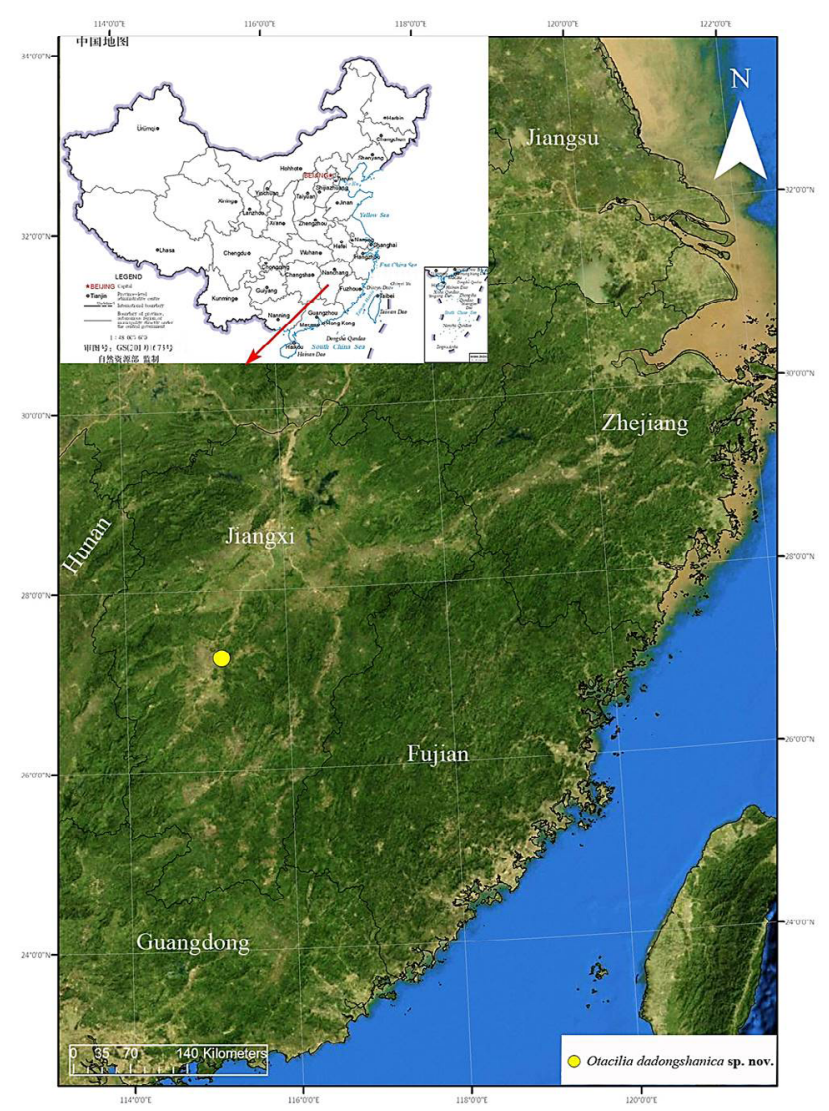

Fig. 5. Collection locality of Otacilia dadongshanica sp. nov. from Jiangxi Province, China.

Statement of conflict of interest

Authors have declared no conflict of interest.

\section{REFERENCES}

Fu, J.Y., Zhang, F. and Zhu, M.S., 2010. Three new species of the genus Otacilia (Araneae: Corinnidae) from Hainan Island, China. J. Nat. Hist., 44: 639650. https://doi.org/10.1080/00222930903437341

Fu, L.N., He, J.C. and Zhang, F., 2015. Species of the genus Otacilia from Hainan Island, China (Araneae: Phrurolithidae). Zool. Syst., 40: 436-450.

Fu, L.N., Jin, C. and Zhang, F., 2014. Three new species of 
the genus Otacilia Thorell (Araneae: Phrurolithidae) from China. Zootaxa, 3869: 483-492. https://doi. org/10.11646/zootaxa.3869.4.10

Fu, L.N., 2016. Taxonomy of the spider genera Otacilia and Phrurolithus from China (Araneae, Phrurolithidae). M. Sc. thesis, Hebei University, Baoding, Hebei, China.

Fu, L.N., Zhang, Z.S. and Zhang, F., 2016a. Description of two new Otacilia species from Anhui, China (Araneae, Phrurolithidae). Acta Zool. Acad. Sci. Hung., 62: 133-142. https://doi.org/10.17109/ AZH.62.2.133.2016

Fu, L.N., Zhang, Z.S. and Zhang, F., 2016b. New Otacilia species from Southwest China (Araneae: Phrurolithidae). Zootaxa, 4107: 197-221. https:// doi.org/10.11646/zootaxa.4107.2.4

Jäger, P. and Dimitrov, D., 2019. Otacilia fansipan sp. nov., the second congener recorded from Vietnam (Arachnida: Araneae: Phrurolithidae). Zootaxa, 4464: 233-240. https://doi.org/10.11646/ zootaxa.4664.2.5

Jäger, P. and Wunderlich, J., 2012. Seven new species of the spider genus Otacilia Thorell 1897 (Araneae: Corinnidae) from China, Laos and Thailand. Beitr. Araneol., 7: 251-271.

Jin, C., Fu, L., Yin, X.C. and Zhang, F., 2016. Four new species of the genus Otacilia Thorell, 1897 from Hunan Province, China (Araneae, Phrurolithidae). ZooKeys, 620: 30-55. https://doi.org/10.3897/ zookeys.620.7982

Kamura, T., 2005. Spiders of the genus Otacilia (Araneae: Corinnidae) from Japan. Acta Arachnol., 53: 87-92. https://doi.org/10.2476/asjaa.53.87

Li, S. and Lin, Y., 2016. Species catalogue of China.
Science Press, Beijing, China.

Liu, K., Xu, X., Xiao, Y.H., Yin, H.Q. and Peng, X.J., 2019. Six new species of Otacilia from southern China (Araneae: Phrurolithidae). Zootaxa, 4585: 438-458. https://doi.org/10.11646/ zootaxa.4585.3.2

Thorell, T., 1897. Viaggio di Leonardo Fea in Birmania e regioni vicine. LXXIII. Secondo saggio sui Ragni birmani. I. Parallelodontes. Tubitelariae. Annl. Mus. Civ. Stor. Nat. Genova, 17: 161-267.

Wang, L.Y., Chen, H.M., Zhou, K.X., Zhang, F. and Zhang, Z.S., 2015. Diversity of spiders in Fanjing Mountain Nature Reserve, Guizhou, China, I: Six new species of Phrurolithidae (Araneae). Zootaxa, 4012: 447-464. https://doi.org/10.11646/ zootaxa.4012.3.2

Wang, L.Y., Zhang, F. and Zhang, Z.S., 2012. Ant-like sac spiders from Jinyun Mountain Natural Reserve of Chongqing, China (Araneae: Corinnidae). Zootaxa, 3431: 37-53. https://doi.org/10.11646/ zootaxa.3431.1.3

World Spider Catalog, 2020. World spider catalog, version 21.0. Natural History Museum, Bern, Bern, Switzerland. Available at: https://wsc.nmbe. ch/resources/archive/catalog_21.0/index.html (accessed on 14 August, 2020).

Yang, T.B., Wang, X.Y. and Yang, Z.Z., 2013. Two new species of genus Otacilia from China (Araneae: Corinnidae). Acta Arachnol. Sin., 22: 9-15.

Zamani, A. and Marusik, Y.M., 2020. A survey of Phrurolithidae (Arachnida: Araneae) in southern Caucasus, Iran and Central Asia. Zootaxa, 4758: 311-329. https://doi.org/10.11646/ zootaxa.4758.2.6 